\title{
Predictors of prostate volume reduction following neoadjuvant cytoreductive androgen suppression
}

\author{
Krishan R. Jethwa, MD', Keith M. Furutani, PhD', Lance A. Mynderse, MD², Torrence M. Wilson, MD², Richard Choo, MD', \\ Bernard F. King, MD³, Eric Bergstralh, MS4 ${ }^{4}$ Brian J. Davis, MD, PhDl \\ 'Department of Radiation Oncology, ${ }^{2}$ Department of Urology, ${ }^{3}$ Department of Diagnostic Radiology, ${ }^{4}$ Department of Biostatistics, \\ Mayo Clinic, Rochester, MN, USA
}

\begin{abstract}
Purpose: Limited duration cytoreductive neoadjuvant hormonal therapy (NHT) is used prior to definitive radiotherapeutic management of prostate cancer to decrease prostate volume. The purpose of this study is to examine the effect of NHT on prostate volume before permanent prostate brachytherapy (PPB), and determine associated predictive factors.

Material and methods: Between June 1998 and April 2012, a total of 1,110 patients underwent PPB and 207 patients underwent NHT. Of these, 189 (91.3\%) underwent detailed planimetric transrectal ultrasound before and after NHT prior to PPB. Regression analysis was used to assess predictors of absolute and percentage change in prostate volume after NHT.

Results: The median duration of NHT was 4.9 months with inter quartile range (IQR), 4.2-6.6 months. Prostatespecific antigen (PSA) reduced by a median of $97 \%$ following NHT. The mean prostate volume before NHT was 62.5 $\pm 22.1 \mathrm{~cm}^{3}$ (IQR: $46-76 \mathrm{~cm}^{3}$ ), and after NHT, it was $37.0 \pm 14.5 \mathrm{~cm}^{3}$ (IQR: 29-47 $\mathrm{cm}^{3}$ ). The mean prostate volume reduction was $23.4 \mathrm{~cm}^{3}(35.9 \%)$. Absolute prostate volume reduction was positively correlated with initial volume and inversely correlated with T-stage, Gleason score, and NCCN risk group. In multivariate regression analyses, initial prostate volume $(p<0.001)$ remained as a significant predictor of absolute and percent prostate volume reduction. Total androgen suppression was associated with greater percent prostate volume reduction than luteinizing hormone releasing hormone agonist (LHRHa) alone $(p=0.001)$.

Conclusions: Prostate volume decreased by approximately one third after 4.9 months of NHT, with total androgen suppression found to be more efficacious in maximizing cytoreduction than LHRHa alone. Initial prostate volume is the greatest predictor for prostate volume reduction.
\end{abstract}

Key words: brachytherapy, neoadjuvant hormonal therapy, prostate cancer, volume.

\section{Purpose}

Permanent prostate brachytherapy (PPB) is a common treatment for early-stage prostate cancer with over 250,000 patients undergoing the procedure in the U.S. since the late 1990's [1]. Limited duration neoadjuvant hormonal therapy (NHT) is often used before PPB to decrease prostate volume, help avoid pubic arch interference during seed placement, and to decrease urinary obstructive symptoms $[2,3,4,5]$. Stone et al. has concluded that NHT may have its greatest benefit in urinary obstructive symptoms in men with a prostate size greater than $50 \mathrm{~cm}^{3}$, and in International Prostate Symptom Score (IPSS) of 15 or greater [3]. Other patients also receive NHT due to intermediate- or high-risk features, similar to approaches validated in external beam radiotherapy (EBRT) [4]. Some studies have also demonstrated a de- crease in neighboring organ toxicity from radiotherapy in patients first treated with NHT versus those not treated with NHT [6,7]. While NHT has many potential therapeutic advantages, identifying patients who are appropriate candidates for NHT remains a subject of interest, as its use must be balanced with the potential acute and late side effects of hormonal therapy.

Neoadjuvant hormonal therapy has been shown to decrease prostate size by 10.8-54.0\% before definitive management, and the extent of downsizing is related to the duration of NHT $[3,8,9,10,11,12,13,14,15,16,17,18,19,20,21,22$, $23,24,25,26,27]$. A randomized trial by Gleave et al. found a decrease of $37 \%$ in transrectal ultrasound (TRUS)-determined prostate volume when three months of NHT were given, versus $45 \%$ when eight months of NHT were given before prostatectomy [8]. Studies have demonstrated 
an advantage with using total androgen suppression (TAS) with a combination of luteinizing hormone releasing hormone agonist (LHRHa) and antiandrogen compared to LHRHa alone [15]. Similarly, studies have demonstrated an advantage of LHRHa over antiandrogen alone [11,17]. However, no published studies have examined differences between medications within classes or the predictive ability of pre-treatment variables, such as, T-stage, Gleason score, pre-treatment prostate specific antigen (PSA), and National Comprehensive Cancer Network (NCCN) risk stratification in regard to prostate volume reduction following NHT. The goals of this study are to examine the degree of pre-PPB prostate size

Table 1. Characteristics of 189 neoadjuvant hormonal therapy patients treated with brachytherapy

\begin{tabular}{lc} 
Factors & Patients, No. \\
\hline Age, years & $70 \pm 5.9(55-86)$ \\
\hline Mean \pm SD (range) & \\
\hline Clinical stage & $120(65.6 \%)$ \\
\hline T1c & $48(26.2 \%)$ \\
\hline T2a & $8(4.4 \%)$ \\
\hline T2c & $4(2.2 \%)$ \\
\hline T3a & $2(1.1 \%)$ \\
\hline T3b & $1(0.5 \%)$ \\
\hline n/a & 6 \\
\hline
\end{tabular}

\begin{tabular}{lc}
\hline Gleason score & \\
\hline 5 & $3(1.6 \%)$ \\
\hline 6 & $127(67.2 \%)$ \\
\hline 7 & $53(28.0 \%)$ \\
\hline 8 & $6(3.2 \%)$ \\
\hline
\end{tabular}

\begin{tabular}{lc}
\hline Pre-NHT PSA group & \\
\hline$<10 \mathrm{ng} / \mathrm{ml}$ & $141(74.6 \%)$ \\
\hline $10-20 \mathrm{ng} / \mathrm{ml}$ & $45(23.8 \%)$ \\
\hline $20 \mathrm{ng} / \mathrm{ml}$ & $3(1.6 \%)$ \\
\hline NCCN risk stratification & $92(50.3 \%)$ \\
\hline Low & $81(44.3 \%)$ \\
\hline Intermediate & $10(5.5 \%)$ \\
\hline High & 6 \\
\hline D/a & $4.9(4.2,6.6)$
\end{tabular}

NHT - neoadjuvant hormonal therapy, PSA - prostate specific antigen, NCCN National Comprehensive Cancer Network, IQR - interquartile range, SD - standard deviation reduction after NHT, and the influence of pre-treatment variables on the magnitude of prostate volume reduction.

\section{Material and methods}

Between June 1998 and April 2012, a total of 1,110 consecutive patients with early-stage prostate cancer were treated by PPB at our institution and provided research authorization. Of these patients, 207 patients received NHT and 189 (91.3\%) underwent TRUS before and after NHT. All patients received an LHRHa. Patients were treated with NHT for one or more reasons: 1) to decrease prostate size in order to minimize pubic arch interference; 2) to decrease prostate size in order to decrease patient's urinary obstructive symptoms, so that they may be more appropriate PPB candidates; and/or 3) to enhance treatment efficacy in patients with intermediate or high risk features. Of the 207 patients receiving LHRH agonists, 194 patients (93.2\%) received leuprolide, while $13(6.8 \%)$ received goserelin. Ninety-two $(44.4 \%)$ patients received TAS, while 115 (56.6\%) received LHRHa alone. A total of $52.2 \%$ of patients receiving LHRH antagonist alone received short course bicalutamide for coverage of possible testosterone flare. Of these patients, the median duration of bicalutamide was 10 days, and mean was 13.8 days (range, 7-30 days). Baseline characteristics of all patients in the population including age, presenting clinical stage, presenting PSA value, and Gleason score were available for analysis.

Detailed measurements of prostate volume were performed by TRUS before and after NHT. One of six experienced ultrasonographers manually contoured the prostate gland as it appeared on each TRUS axial image at $5 \mathrm{~mm}$ increments using a TRUS probe holder, stepper and stabilization device (Barzell-Whitmore, Sarasota, FL, USA) used for PPB. Prostate volume, in cubic centimeters $\left(\mathrm{cm}^{3}\right)$, was determined, using both a three-dimensional manual planimetry method and a conventional prolate spheroid measurement, as they are considered to be the most accurate measurements of prostate volume [28,29].

Mean prostate volume and PSA comparisons before and after NHT were made with matched pair's $t$-tests. Differences in mean volume reductions and PSA changes between treatment groups were compared using Student's $t$-test. Bivariate and multivariable association between absolute and percentage prostate volume reduction and pre-treatment variables were made using linear regression analysis. Results were reported as unstandardized multivariate regression coefficients and the associated standard errors. All statistical analysis was performed using JMP version 10.0, and SAS version 9.3. A $p$-value $<0.05$ was considered significant.

\section{Results}

The patients' demographics are provided in Table 1. The median age at the time of NHT was $70 \pm 5.9$ years (range: 55-86 years). The majority of patients were diagnosed with low-risk features, T1c/T2a (91.8\%), Gleason score $6(67.2 \%)$, and with pre-treatment PSA of less than $10 \mathrm{ng} / \mathrm{ml}(74.6 \%)$. Patients treated with goserelin as compared to leuprolide were diagnosed with more 
Table 2. Prostate volume and prostate specific antigen measurements before and after neoadjuvant hormonal therapy

\begin{tabular}{lcccc}
\hline End-point & Pre-NHT & Post-NHT & Absolute reduction & Percent reduction \\
\hline Prostate volume $\left(\mathrm{cm}^{3}\right)$ & 189 & 189 & 189 & 189 \\
\hline$n$ & $63(46-76)$ & $37(29-47)$ & $23(12-32)$ & $38 \%(27-45 \%)$ \\
\hline Median (IQR) & $63 \pm 22$ & $39 \pm 14$ & $23 \pm 13$ & $36 \pm 13 \%$ \\
\hline Mean \pm SD & 189 & 179 & 179 & 179 \\
\hline PSA (ng/ml) & $6.5(4.9-10.1)$ & $0.17(0.11-0.5)$ & $6.2(4.6-9.6)$ & $97 \%(91-98 \%)$ \\
\hline$n$ & $7.9 \pm 5.2$ & $0.44 \pm 0.63$ & $7.5 \pm 5.2$ & $94 \pm 8 \%$
\end{tabular}

NHT - neoadjuvant hormonal therapy, PSA - prostate specific antigen, IQR - interquartile range, SD - standard deviation

advanced T-stage $(p=0.049)$. Patients treated with TAS as compared to LHRHa alone were diagnosed with less advanced T-stage $(p<0.0001)$, lower NCCN risk stratification $(p=0.0003)$, and larger pre-NHT prostate volume with means of $70.4 \mathrm{~cm}^{3}$ and $53.5 \mathrm{~cm}^{3}(p<0.0001)$. Other patient characteristics were not significantly different between the subgroup of patients treated with leuprolide versus goserelin or TAS versus LHRHa alone, including age, Gleason score, and pre-treatment PSA.

The median duration of NHT was 4.9 months (range: 0.77-23.77 months). Most patients $(97.4 \%)$ received at least 3 months of NHT; $81.0 \%$ received at least 4 months. Those treated with leuprolide had a median treatment duration of 5.0 months (range: 0.77-23.77 months) while those treated with goserelin had a median duration of 4.4 months (range, 3.43-8.5 months). Student's $t$-test demonstrated a difference between the mean duration between these groups with $p=0.03$.

The mean TRUS-determined prostate volume before NHT was $62.5 \pm 22.1 \mathrm{~cm}^{3}$ (IQR: $46-76 \mathrm{~cm}^{3}$ ) and after NHT, it was $39.0 \pm 14.0 \mathrm{~cm}^{3}$ (IQR: $\left.29-47 \mathrm{~cm}^{3}\right)$, resulting in a mean percent reduction of $35.9 \%$ (Table 2 ) with a maximum volume reduction of $63.1 \%$. Figure 1 shows the distribution of prostate volumes before and after the start of NHT. Figure $2 \mathrm{~A}$ demonstrates that the absolute volume change is strongly correlated $(r=0.77, p<0.001)$ with the initial volume. In Figure 2B, the percentage volume reduction is shown.

The median PSA before NHT was $6.5 \mathrm{ng} / \mathrm{ml}$ (IQR, $4.9-10.1 \mathrm{ng} / \mathrm{ml})$, and after NHT it was $0.17 \mathrm{ng} / \mathrm{ml}$ (IQR $0.11-0.5 \mathrm{ng} / \mathrm{ml}$ ) (Table 2). This resulted in a mean percent PSA reduction of $93.7 \%$. A total of $60(31.7 \%)$ patients had PSA levels less than $0.15 \mathrm{ng} / \mathrm{ml}$ after NHT.

Absolute and percent prostate volume reductions were analyzed using bivariate and multivariate regression analysis (Table 3 ). Absolute prostate volume reduction was positively correlated with initial volume and inversely correlated with T-stage, Gleason score, and NCCN risk group. In multivariate regression analysis, only initial prostate volume $(p<0.001)$ remained as a significant predictor of absolute volume reduction. Initial prostate volume and T-stage were predictive of percent prostate volume reduction on univariate analysis, however, only initial prostate volume remained as significant on multivariate regression analysis.

The reduction in prostate volume and PSA after NHT was evaluated separately by type of LHRHa: leuprolide $(n=177)$ versus goserelin $(n=12)$, and total androgen suppression $(n=92)$ versus LHRHa alone $(n=97)$. The pre-treatment prostate volumes for the leuprolide versus goserelin comparison were not significantly different ( $p=0.97)$, however, there was a difference between those receiving TAS versus LHRHa alone $(p<0.001)$ with a mean of $70.4 \mathrm{~cm}^{3}$ and $53.5 \mathrm{~cm}^{3}$, respectively. The mean percent prostate volume reduction was $36.5 \%$ and $29.8 \%$ for the leuprolide and goserelin groups, respectively. Student's $t$-test did not demonstrate a significant difference between means of both groups $(p=0.18)$. Mean percent prostate volume reduction was $38.8 \%$ and $33.5 \%$ for the TAS and LHRHa alone groups, respectively $(p=0.001)$.

The change in PSA after NHT was similarly examined as a function of type of androgen suppression. No significant difference was seen in pre-treatment PSA between those treated with leuprolide or goserelin $(p=0.06)$, or between those treated with TAS compared to LHRHa

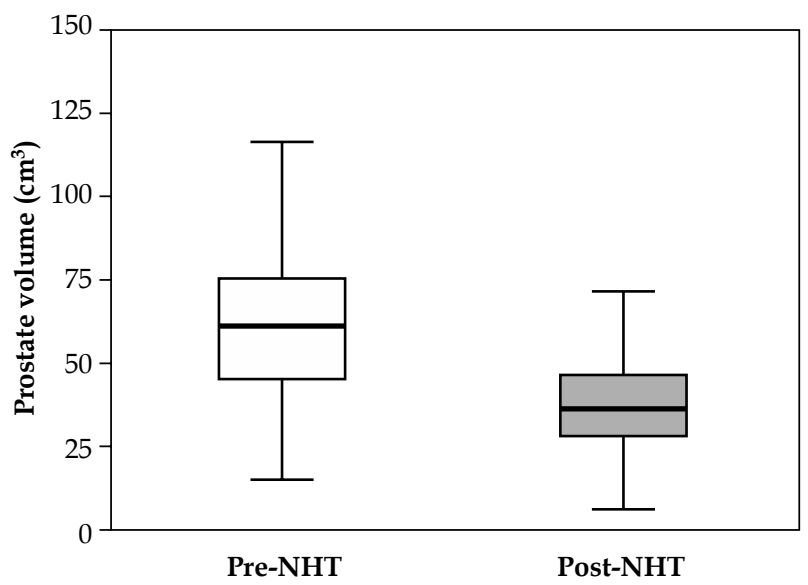

Fig. 1. Distribution of prostate volume before and after neoadjuvant hormonal therapy 
A

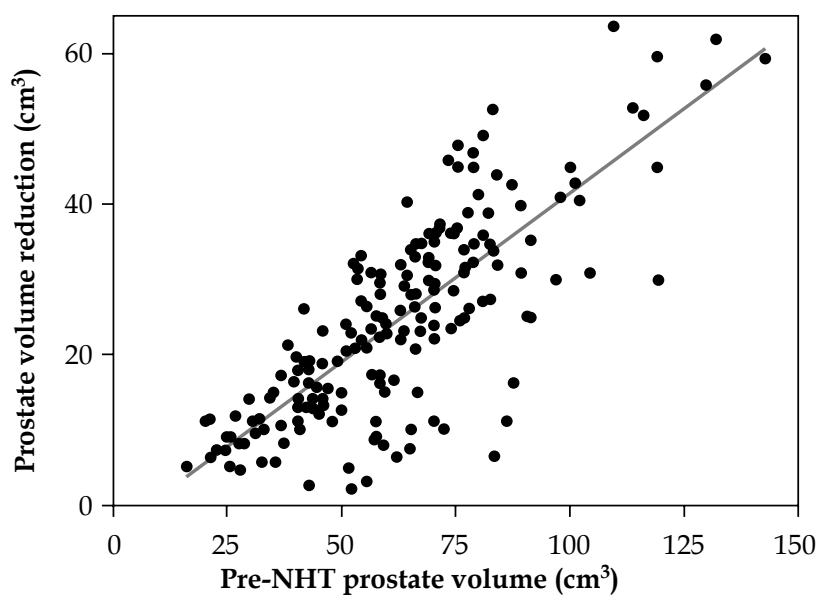

B

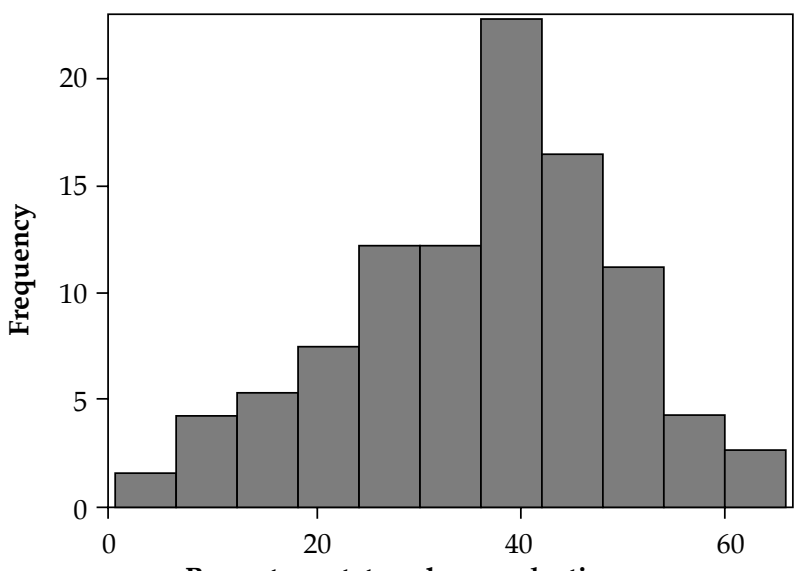

Fig. 2. Change in prostate volume after neoadjuvant hormonal therapy. A) Scatter plot of absolute reduction vs. initial volume.

B) Histogram of percentage reduction in prostate volume

alone $(p=0.20)$. The mean percent PSA reduction was $93.8 \%$ and $91.8 \%$ for the leuprolide and goserelin groups, respectively. The mean percent PSA reduction was $95.5 \%$ and $91.4 \%$ for those treated with TAS and LHRHa alone, respectively. Student's $t$-test did not identify a difference between mean percent PSA reduction in those treated with leuprolide compared to goserelin $(p=0.36)$. Howev- er, there was a significant difference between those treated with TAS compared to LHRHa alone $(p<0.001)$.

\section{Discussion}

We have examined the use of cytoreductive NHT and associated predictive factors in a series of patients under-

Table 3. Regression analysis between pretreatment variables and treatment endpoints of absolute and percent prostate volume reduction

\begin{tabular}{|c|c|c|c|c|}
\hline & \multicolumn{2}{|c|}{ Univariable } & \multicolumn{2}{|c|}{ Multivariable } \\
\hline & Beta (SE) & $p$-value & Beta (SE) & $p$-value \\
\hline \multicolumn{5}{|c|}{ a. $Y=$ absolute volume reduction, $\mathrm{cm}^{3}$} \\
\hline Pre-NHT volume & $0.48(0.03)$ & $<0.001$ & $0.48(0.03)$ & $<0.0001$ \\
\hline Age & $0.07(0.16)$ & 0.68 & $0.06(0.11)$ & 0.55 \\
\hline Pre-NHT PSA & $0.01(0.19)$ & 0.94 & $-0.12(0.15)$ & 0.45 \\
\hline T-stage* & $-3.7(1.1)$ & 0.001 & $-0.8(0.8)$ & 0.34 \\
\hline Gleason score & $-6.9(1.7)$ & $<0.001$ & $-0.7(1.7)$ & 0.70 \\
\hline NCCN risk group** & $-4.5(1.6)$ & 0.006 & $2.2(1.9)$ & 0.24 \\
\hline Duration of NHT & $-0.46(0.35)$ & 0.19 & $-0.16(0.23)$ & 0.50 \\
\hline \multicolumn{5}{|c|}{ b. $Y=$ percent volume reduction, $\%$} \\
\hline Pre-NHT volume & $0.002(0.0004)$ & $<0.0001$ & $0.002(0.0004)$ & 0.0003 \\
\hline Age & $0.11(0.16)$ & 0.51 & $0.002(0.002)$ & 0.30 \\
\hline Pre-NHT PSA & $-0.08(0.19)$ & 0.68 & $-0.002(0.002)$ & 0.38 \\
\hline T-stage* & $-2.3(1.1)$ & 0.047 & $-0.015(0.01)$ & 0.23 \\
\hline Gleason score & $-2.6(1.7)$ & 0.13 & $-0.01(0.03)$ & 0.74 \\
\hline NCCN risk group** & $-1.8(1.6)$ & 0.26 & $0.02(0.004)$ & 0.42 \\
\hline Duration of NHT & $-0.42(0.3)$ & 0.23 & $-0.003(0.004)$ & 0.35 \\
\hline
\end{tabular}

NHT - neoadjuvant hormonal therapy, PSA - prostate specific antigen, NCCN - National Comprehensive Cancer Network, SE - standard error

${ }^{*}$ Coded as: $1=T 1 x, 2=T 2 x, 3=T 3 x ;{ }^{* *}$ Coded as: $0=$ low, $1=$ int, $2=$ high

${ }^{*}$ Univariate Spearman correlation coefficients ( $p$-value); ${ }^{* *}$ Multivariate regression correlation coefficients ( $p$-value); ${ }^{*}$ Statistical significance with $p<0.05$ 
going PPB. In a recent survey of brachytherapy practice by Buyyounouski et al., it is confirmed that this is a common treatment approach; $63 \%$ of respondents reported using androgen deprivation in conjunction with $\mathrm{PPB}$, with $72 \%$ of those employing NHT for purposes of cytoreduction [30]. In this survey, the majority of brachytherapists indicated they prescribe NHT for 3 or 4 months. In terms of prostate volume, the maximum volume that practitioners indicated they would implant was $>60 \mathrm{~cm}^{3}$ in $25 \%$ of respondents, and $>100 \mathrm{~cm}^{3}$ in $5 \%$. Of note, a previous survey study published in 1998 by Prestidge et al., only 9\% of respondents indicated they would implant prostates larger than $60 \mathrm{~cm}^{3}$ [31].

While current American Brachytherapy Society guidelines indicate that a prostate size $>60 \mathrm{~cm}^{3}$, is a relative contraindication to brachytherapy; in practice, few patients may be ruled out as candidates for PPB based on size criteria alone. If patients are willing to undergo NHT, then patients may experience sufficient prostate cytoreduction such that the prostate size decreases below $60 \mathrm{~cm}^{3}$. In the present study, $53 \%$ of patients presented with a prostate size $>60 \mathrm{~cm}^{3}$, including one patient with a size of $138 \mathrm{~cm}^{3}$. Following NHT, only $8 \%$ of patients had prostate size $>60 \mathrm{~cm}^{3}$, but were nonetheless still able to undergo PPB. Implantation of prostates greater than $100 \mathrm{~cm}^{3}$ is possible as described by Stone and Stock in a series of 34 patients [32] In a report by Grado, a patient with prostate size of $165 \mathrm{~cm}^{3}$ underwent PPB [33].

In the series described here, prostate volume decreased by a mean of $35.9 \%$ when it was given for 4.9 months. The results given in Table 4 are consistent with those seen in previous studies regarding the degree of cytoreduction with NHT $[3,8,9,10,11,12,13,14,15,16,17,18,19,20,21,22,23$, $24,25,26]$. The largest study to date randomized 547 patients to either three or eight months of NHT. This study found a volume reduction of $37 \%$ after three months and $45 \%$ after eight months [8]. Crook et al. reported similar findings in a randomized trial of 378 patients who received either three or eight months of NHT prior to EBRT; patients receiving three months of NHT had a $29.3 \%$ reduction while those receiving eight months had a $46.3 \%$ reduction $[9,10]$. Thus, based upon these studies $[8,9,10]$, and the collective literature on this topic $[3,11,12,13,14,15$, $16,17,18,19,20,21,22,23,24,25,26]$, a useful estimate is that prostate volume decreases by approximately one third after 3-4 months of NHT in the majority of patients.

A significant decrease in prostate size after NHT was not found for all patients. Three patients had a negligible $(<4 \%)$ decrease. The factors that predict if a patient will have very little or no cytoreduction at present are unknown. This finding may in part be attributable to differences in TRUS operator technique, or interobserver variability in prostate segmentation by TRUS [34]. This finding is also consistent with previous studies that have demonstrated significant limitations in accuracy due to interobserver and intraobserver variability $[35,36,37]$. Zelefsky et al. reported that 2 of 22 patients had no prostate volume reduction after TAS [25]. All imaging modalities, including TRUS, are subject to inter- and intraobserver variability, which may account for a portion of the absence of volume reduction after NHT [35,36, $37,38,39,40]$.

Similarly, to other series, this study illustrated a significant reduction in PSA following NHT, with a mean reduction in PSA of $93.7 \%$. In the comparison of three versus eight months of NHT by Gleave et al., a PSA reduction of $98 \%$ was seen after three months of NHT [8]. Similarly, Crook et al. found a $97.3 \%$ reduction in PSA after three months, and a $98.5 \%$ reduction after 8 months [10]. The findings in this study did not reveal a significant difference in PSA reduction between those receiving leuprolide versus goserelin. However, there was a difference in those receiving TAS compared to LHRHa alone.

To date, few studies have evaluated NHT treatment effect in terms of prostate volume reduction as a function of pre-treatment variables of patient age, T-stage, Gleason score, pre-treatment PSA, or overall NCCN risk stratification. In the present study, T-stage, Gleason score, and NCCN risk group demonstrated an inverse correlation with absolute prostate volume reduction on univariate analysis of correlation. On multivariate regression analysis with adjustment for initial volume, none of these factors remained significant. Initial prostate volume and T-stage were the only significant predictors of percentage reduction in volume. Initial prostate volume was the only variable which remained significant on multivariate regression analysis. Our data confirms that the prognostic pre-treatment variables of Gleason score and clinical stage do not influence the degree of prostate gland regression with NHT. Other predictors of absolute volume reduction may be clinically useful in order to determine if NHT will result in a prostate volume $<60 \mathrm{~cm}^{3}[2,6,7,22]$.

Some studies have suggested greater prostate volume reductions with the use of LHRHa versus antiandrogen alone. Stone et al. analyzed 299 patients treated with 3 months' total androgen suppression (251 patients) with LHRHa plus antiandrogen, LHRHa alone (41 patients), and antiandrogen alone (7 patients), and demonstrated prostate volume reductions of $32.8 \%, 27.6 \%$, and $10.8 \%$, respectively [11]. Henderson et al. identified a three-fold difference in patients treated with LHRHa versus antiandrogen, in favor of LHRHa [17]. Another subset analysis revealed that an LHRHa combined with antiandrogen resulted in larger prostate volume reduction than that of LHRHa alone (35\% vs. $30 \%$ ) [15]. This series was consistent with previous findings with prostate volume reductions of $38.8 \%$ and $33.5 \%$ in the TAS and LHRHa alone groups, respectively $(p=0.001)$.

These data show that NHT with leuprolide or goserelin resulted in statistically indistinguishable volume reductions. However, a limitation of this finding is the small number of patients receiving goserelin $(n=12)$. Another limitation is that the mean duration of NHT was different between the two groups, with patients receiving goserelin having a mean duration of therapy approximately one month shorter. As noted, other studies have compared three months vs. eight months, a sufficient time interval, in which to observe differences in the magnitude of cytoreduction.

This study has limitations, in that it was retrospective in nature and is subject to selection biases for ther- 


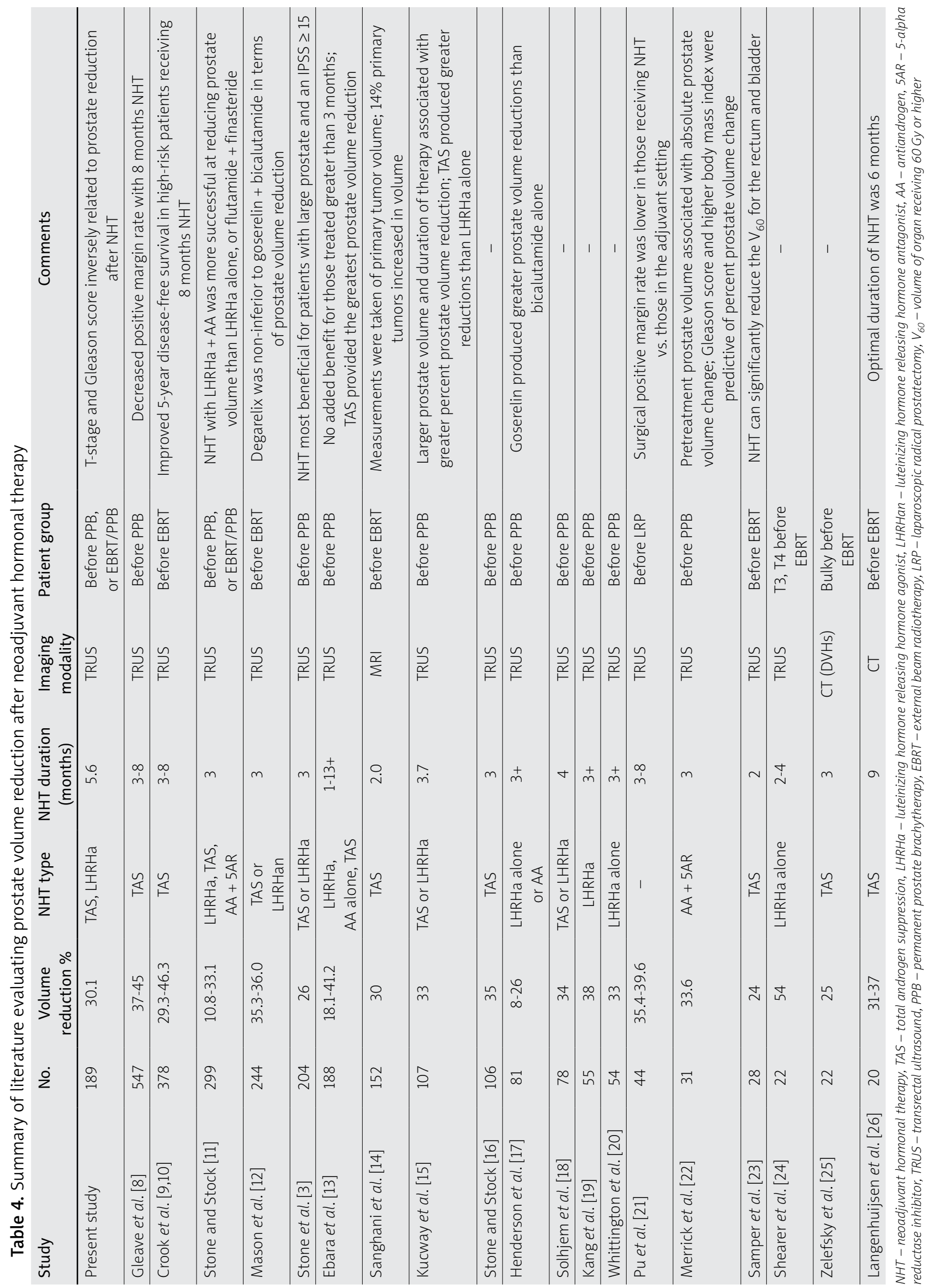


apy. While this study is larger than many similar studies (range 20-547), the cohort size included less than 200 patients, and the comparison between leuprolide and goserelin is statistically limited with 12 patients having received goserelin. The homogeneity of the patient cohort, with the majority having low-risk disease, may limit the capacity of this data set to identify any associations between pre-treatment variables and the degree of prostate gland downsizing. Additionally, inter- and intra-observer variability in prostate volume determination may have also affected this study, however, it is noted that the ultrasonographers involved in the study were dedicated and had additional training relative to prostate ultrasonography.

\section{Conclusions}

Neoadjuvant hormonal therapy remains a useful tool in managing patients with enlarged prostates who are otherwise suitable candidates for permanent prostate brachytherapy. In this series, prostate volume decreased by approximately one third after 4.9 months of NHT with a maximum reduction of $63 \%$ observed. Initial prostate volume is the greatest predictor of prostate volume reduction following NHT.

\section{Disclosure}

A portion of this work was funded by a research grant from Takeda U.K., Ltd.

Authors report no conflict of interest.

\section{References}

1. Davis BJ, Horwitz EM, Lee WR et al. American Brachytherapy Society consensus guidelines for transrectal ultrasound-guided permanent prostate brachytherapy. Brachytherapy 2012; 11: 6-19.

2. Lee WR. The role of androgen deprivation therapy combined with prostate brachytherapy. Urology 2002; 60 (3 Suppl 1): 3944; discussion 44.

3. Stone NN, Marshall DT, Stone JJ et al. Does neoadjuvant hormonal therapy improve urinary function when given to men with large prostates undergoing prostate brachytherapy? J Urol 2010; 183: 634-639.

4. Zumsteg ZS, Zelefsky MJ. Short-term androgen deprivation therapy for patients with intermediate-risk prostate cancer undergoing dose-escalated radiotherapy: The standard of care? Lancet Oncol 2012; 13: e259-269.

5. Crook J, McLean M, Catton C et al. Factors influencing risk of acute urinary retention after TRUS-guided permanent prostate seed implantation. Int J Radiat Oncol Biol Phys 2002; 52: 453-460.

6. Forman JD, Kumar R, Haas G et al. Neoadjuvant hormonal downsizing of localized carcinoma of the prostate: Effects on the volume of normal tissue irradiation. Cancer Invest 1995; 13: 8-15.

7. Zelefsky MJ, Harrison A. Neoadjuvant androgen ablation prior to radiotherapy for prostate cancer: Reducing the potential morbidity of therapy. Urology 1997; 49 (3A Suppl): 38-45.

8. Gleave ME, Goldenberg SL, Chin JL et al. Randomized comparative study of 3 versus 8-month neoadjuvant hormonal therapy before radical prostatectomy: Biochemical and pathological effects. J Urol 2001; 166: 500-506; discussion 506-507.
9. Crook J, Ludgate C, Malone S et al. Final report of multicenter Canadian phase III randomized trial of 3 versus 8 months of neoadjuvant androgen deprivation therapy before conventional-dose radiotherapy for clinically localized prostate cancer. Int J Radiat Oncol Biol Phys 2009; 73: 327-333.

10. Crook J, Ludgate C, Malone $S$ et al. Report of a multicenter Canadian phase III randomized trial of 3 months vs. 8 months neoadjuvant androgen deprivation before standard-dose radiotherapy for clinically localized prostate cancer. Int J Radiat Oncol Biol Phys 2004; 60: 15-23.

11. Stone NN, Stock RG. The effect of brachytherapy, external beam irradiation and hormonal therapy on prostate volume. J Urol 2007; 177: 925-928.

12. Mason M, Maldonado Pijoan X, Steidle C et al. Neoadjuvant androgen deprivation therapy for prostate volume reduction, lower urinary tract symptom relief and quality of life improvement in men with intermediate- to high-risk prostate cancer: A randomised non-inferiority trial of degarelix versus goserelin plus bicalutamide. Clin Oncol (R Coll Radiol) 2013; 25: 190-196.

13. Ebara S, Manabe D, Kobayashi Y et al. The efficacy of neoadjuvant androgen deprivation therapy as a prostate volume reduction before brachytherapy for clinically localized prostate cancer. Acta Med Okayama 2007; 61: 335-340.

14. Sanghani MV, Schultz D, Tempany CM et al. Quantifying the change in endorectal magnetic resonance imaging-defined tumor volume during neoadjuvant androgen suppression therapy in patients with prostate cancer. Urology 2003; 62: 487-491.

15. Kucway R, Vicini F, Huang R et al. Prostate volume reduction with androgen deprivation therapy before interstitial brachytherapy. J Urol 2002; 167: 2443-2447.

16. Stone NN, Stock RG. Neoadjuvant hormonal therapy improves the outcomes of patients undergoing radioactive seed implantation for localized prostate cancer. Mol Urol 1999; 3: 239-244.

17. Henderson A, Langley SE, Laing RW. Is bicalutamide equivalent to goserelin for prostate volume reduction before radiation therapy? A prospective, observational study. Clin Oncol (R Coll Radiol) 2003; 15: 318-321.

18. Solhjem MC, Davis BJ, Pisansky TM et al. Prostate volume before and after permanent prostate brachytherapy in patients receiving neoadjuvant androgen suppression. Cancer J 2004; 10: 343-348.

19. Kang SK, Chou RH, Dodge RK et al. Acute urinary toxicity following transperineal prostate brachytherapy using a modified quimby loading method. Int J Radiat Oncol Biol Phys 2001; 50: 937-945.

20. Whittington R, Broderick GA, Arger P et al. The effect of androgen deprivation on the early changes in prostate volume following transperineal ultrasound guided interstitial therapy for localized carcinoma of the prostate. Int J Radiat Oncol Biol Phys 1999; 44: 1107-1110.

21. Pu XY, Wang XH, Wu YL et al. Comparative study of the impact of 3-versus 8-month neoadjuvant hormonal therapy on outcome of laparoscopic radical prostatectomy. J Cancer Res Clin Oncol 2007; 133: 555-562.

22. Merrick GS, Butler WM, Wallner KE et al. Efficacy of neoadjuvant bicalutamide and dutasteride as a cytoreductive regimen before prostate brachytherapy. Urology 2006; 68: 116-120.

23. Samper PM, López Carrizosa MC, Pérez Casas A et al. Impact of neoadjuvant hormonal therapy on dose-volume histograms in patients with localized prostate cancer under radical radiation therapy. Clin Transl Oncol 2006; 8: 599-605.

24. Shearer RJ, Davies JH, Gelister JS et al. Hormonal cytoreduction and radiotherapy for carcinoma of the prostate. $\mathrm{Br} \mathrm{J} \mathrm{Urol}$ 1992; 69: 521-524. 
25. Zelefsky MJ, Leibel SA, Burman CM et al. Neoadjuvant hormonal therapy improves the therapeutic ratio in patients with bulky prostatic cancer treated with three-dimensional conformal radiation therapy. Int J Radiat Oncol Biol Phys 1994; 29: 755-761.

26. Langenhuijsen JF, van Lin EN, Hoffmann AL et al. Neoadjuvant androgen deprivation for prostate volume reduction: The optimal duration in prostate cancer radiotherapy. Urol Oncol 2011; 29: 52-57.

27. Stone NN, Clejan SJ. Response of prostate volume, prostate-specific antigen, and testosterone to flutamide in men with benign prostatic hyperplasia. J Androl 1991; 12: 376-380.

28. Terris MK, Stamey TA. Determination of prostate volume by transrectal ultrasound. J Urol 1991; 145: 984-987.

29. Eri LM, Thomassen H, Brennhovd B et al. Accuracy and repeatability of prostate volume measurements by transrectal ultrasound. Prostate Cancer Prostatic Dis 2002; 5: 273-278.

30. Buyyounouski MK, Davis BJ, Prestidge BR et al. A survey of current clinical practice in permanent and temporary prostate brachytherapy: 2010 update. Brachytherapy 2012; 11: 299305.

31. Prestidge BR, Prete JJ, Buchholz TA et al. A survey of current clinical practice of permanent prostate brachytherapy in the united states. Int J Radiat Oncol Biol Phys 1998; 40: 461-465.

32. Stone NN, Stock RG. Prostate brachytherapy in men with gland volume of 100cc or greater: Technique, cancer control, and morbidity. Brachytherapy 2013; 12: 217-221.

33. Grado GL. Techniques to achieve optimal seed placement in salvage and primary brachytherapy for prostate cancer. Tech Urol 2000; 6: 157-165.

34. Sech S, Montoya J, Girman CJ et al. Interexaminer reliability of transrectal ultrasound for estimating prostate volume. J Urol 2001; 166: 125-129.

35. Speight JL, Shinohara K, Pickett B et al. Prostate volume change after radioactive seed implantation: Possible benefit of improved dose volume histogram with perioperative steroid. Int J Radiat Oncol Biol Phys 2000; 48: 1461-1467.

36. Solhjem MC, Davis BJ, Pisansky TM et al. Prostate volume measurement by transrectal ultrasound and computed tomography before and after permanent prostate brachytherapy. Int J Radiat Oncol Biol Phys 2004; 60: 767-776.

37. Smith S, Wallner K, Merrick G et al. Interpretation of preversus postimplant TRUS images. Med Phys 2003; 30: 920-924.

38. Dubois DF, Prestidge BR, Hotchkiss LA et al. Intraobserver and interobserver variability of MR imaging- and CT-derived prostate volumes after transperineal interstitial permanent prostate brachytherapy. Radiology 1998; 207: 785-789.

39. Lee WR, Roach M 3rd, Michalski J et al. Interobserver variability leads to significant differences in quantifiers of prostate implant adequacy. Int J Radiat Oncol Biol Phys 2002; 54: 457-461.

40. Al-Qaisieh B, Ash D, Bottomley DM et al. Impact of prostate volume evaluation by different observers on CT-based post-implant dosimetry. Radiother Oncol 2002; 62: 267-273. 